\title{
Methodology of Comparative Research in Education: Role and Significance
}

\author{
Danijela Milošević ${ }^{1^{*}}$, Jelena Maksimovićc \\ ${ }^{1}$ University of Niš, Faculty of Philosophy, Department of Pedagogy, Niš, Serbia, \\ e-mail: d.milosevic-15811@filfak.ni.ac.rs; jelena.maksimovic@filfak.ni.ac.rs
}

\begin{abstract}
Research interest in the comparison of education systems emerged parallel with the study of social development and the general globalization of social resources. The contemporary context of research discourse puts researchers in a position of necessary collaboration and partnership, with a special emphasis on the comparative analysis of educational phenomena. The aim of this study is the analysis of the theoretical understandings of the role of comparative research in the cognition of pedagogical phenomena as well as the transformation of the comparative methodological apparatus in the contemporary context. The research tasks are aimed at analyzing the historical development of comparative research, epistemology, the function of comparative research in pedagogy, as well as its importance in pedagogy. The importance of developing pluralism in the methodological approach of comparative research is emphasized in order to strengthen research capacities for its future development in pedagogical sciences. The study relies on the historical method and the method of source content analysis.

Keywords: epistemology of comparative research, comparative pedagogy, quantitative methodological approach, qualitative methodological approach, education systems.
\end{abstract}

\section{Introduction}

The development of comparative pedagogy has gone through various crises of terminological determination precisely because its subject has been studied by other social sciences. An agreement in research methodology was achieved during the twentieth century, so it can be said that its epistemological field is based on positivism, relativism and historical functionalism (Schneider et al., 1961; Bray, Adamson and Mason, 2007; Epstein, 2008; Kaloyannaki and Kazamias, 2009; Manzon, 2018). Such a foundation has contributed to the development of comparative research that is highly susceptive to geopolitical, national and social demands and interests. Therefore, it is highlighted that the place of comparative research is between institutional structures and intellectual discourse (Manzon, 2018).

What distinguishes the methodology of comparative research from other research is the approach it uses. The area of interest of comparativists is focused on different cultures and countries, but also other education systems. Comparativists start from what can be compared realistically, using all the research methods that other researchers employ in their investigations (Phillips, 2006). Therefore, comparative research involves a huge range of approaches that are available to researchers and that depend on the area that is being investigated. Hence, it can be said that the interest in comparative research is based on the discovery of many pedagogical issues and problems. In that respect, the function and contribution of comparative pedagogy is reflected in studying the content, methods and techniques of the educational process, but its application is also visible in a wider social context. The methodology of comparative research in pedagogy is considered precisely through the aim of this paper, which includes the analysis of the theoretical understandings of the role of comparative research in the cognition of pedagogical phenomena as well as the transformation of the comparative methodological apparatus in the contemporary context. The study emphasizes the importance of comparative research in pedagogical epistemology, with special reference to the place of comparative research and its role in the changes of education systems. The following are examined by conducting research tasks: the development of comparative research epistemology; the methodological apparatus of comparative research; the function of comparative research in pedagogy; and the place that comparative research has in pedagogy. The study relies on the historical method and the method of source content analysis. 


\section{History of comparative research}

The impetus for conducting comparative research in education has comprised a number of reasons: political and ideological (a necessity to establish education on different foundations after changing sociopolitical circumstances, liberation from colonialism, etc.), economic (the introduction of changes to encourage economic progress), cultural (the cooperation of countries that have a similar tradition, culture and language), pedagogical (solving problems common to a number of countries, implementing reforms), etc. (Halls, 1990).

During its development, there have been disagreements among authors regarding the origin and development of comparative research (Phillips, 2006; Bray, Adamson and Mason, 2007; Epstein, 2017; Manzon, 2018). They are present even among the most influential researchers (Tamtik, 2014) in terms of the multidimensionality and complexity of the research apparatus of comparative research.

At the beginning of its development, the interests of comparative pedagogy were based on the researchers' initial humanistic side. Namely, on the basis of humanism and democracy, comparative research was aimed at learning the dynamics of educational development, which enabled policy makers to improve the living conditions of citizens. At the end of the Second World War, there were some changes, reflected in the abandonment of the humanistic conception and the emergence of elitism among researchers. Comparative research ceased to be focused on cognition and became an instrument of the state in creating its own socialist and communist apparatus. The role of education in social and economic development was considered, i.e. the answer to the question of how education could contribute to the economic development and democratization of society was sought. Thus, implementing education policy and conducting a successful reform came to the fore, and education policy makers and researchers tried to find the best way to respond to new demands (Mattheou, 2009; Manzon, 2018). Until the late 1930s, the field of comparative pedagogy was still quite limited. It was mainly about understanding and explaining from a historical perspective how and why a certain education system developed in a way different from others. Accelerated development and a strong driver for the implementation of international comparisons in the field of education contributed to the process of globalization, but also to the development of social sciences (and empirical research). Due to the accelerated progress of information and communication technologies, there has been a greater availability of information and a greater mobility of researchers (Spasenović, 2013). It is exactly these reasons that have contributed to the flourishing of comparative research and its focus on important social changes.

Due to the influence of the technological revolution, there has been a growing interest of researchers when it comes to the comparative research of education systems. An adequate analysis and understanding of the education system of any country, as well as other systems (social, political, cultural, etc.), is almost impossible without comparison. That is why comparative research is a necessary instrument of cognition, which opens new dilemmas and questions for researchers. As comparative research is based on the necessary cooperation and establishment of partnerships between researchers from different countries, it is necessary to harmonize the terminology. In pedagogy, the terms comparative education/pedagogy and comparative research are used. However, when the problem of terminological nature is overcome, another one arises. In order to gain a more complete insight into a certain education system and to plan further development processes, it is necessary to have an understanding and knowledge not only of the functioning of education systems, but also of the education policy and practice of both countries (Spasenović, 2013).

Based on the consideration of the history of comparative research, which concerns the first task of this paper, it can be concluded that there are disagreements among authors with regard to its origin and development, which is still ongoing. On the other hand, there are agreements when it comes to changes in its implementation which followed the emergence of globalization and external and internal changes in countries. Comparative research lies between the institutional and intellectual framework. On the one hand, it relies on the need of institutions for comparative analysis in order to develop and improve them through the use of a better model of other institutions. On the other hand, the intellectual need seeks to systematize and establish the rules of ownership. Therefore, this leads to a change in its focus, as well as in the function of the methodological apparatus, which is discussed in the following section.

\section{Methodological apparatus of comparative research}

This section of the study discusses the methodological apparatus of comparative research and its importance in pedagogical practice. Comparative pedagogy is reviewed as a relatively new scientific 
paradigm, as well as the quantitative and qualitative approach in the research of comparative educational phenomena.

Comparative research finds a theoretical basis in the social sciences, so the change in the dominant paradigm in the social sciences has caused a change in comparative pedagogy. This includes the rise of positivism in the 1960s and 1970s and the popularity of postmodernism in the 1980s and 1990s (Crossley, 2000).

In order to further investigate the phenomenon of the research apparatus, Rust et al. (1999: 100) analyzed English-language papers in journals such as: Comparative Education Review published in the USA, Comparative Education published in Great Britain and The International Journal of Educational Development also published in Great Britain. Analyzing papers from the 1960s, they found that $48.5 \%$ were based on literature review and $15.2 \%$ on historical analysis. During the 1980 s and 1990 s, they found a decline in the two categories: $25.7 \%$ of papers were based mainly on literature review and $5 \%$ on historical analysis. Based on the application of interviews and questionnaires, increases are observed in project analysis, as well as in observation and research. In this regard, the use is directed towards the standard instruments of the social sciences. When it comes to investigating the use of methods, based on 427 papers published in 1985, 1987, 1989, 1991, 1993 and 1995, it was found that: $71.2 \%$ of published papers used a qualitative method, $17.3 \%$ used a quantitative method and $10.8 \%$ used a combination of a qualitative and a quantitative method. Their conclusions indicate that there is no tendency for comparative researchers to rely on similar philosophical assumptions. Comparativists tend to see reality subjectively and in multiple ways, rather than objectively and in a uniform manner. Epistemologically, they tend to interact with the subject of research, instead of acting independently and remotely. However, this does not diminish the scientific basis of comparative research. On the contrary, it indicates that the strategies are directed towards the users of that research.

The main objection to macro research is that it does not reach the coverage and understanding of everyday school life, which is crucial for the educational process. The study of macro problems, that is, the study of school systems in all their dimensions, does not enable the perception of all specific pedagogical problems. Thus, a micro approach in the perception of education systems is recommended, which narrows the area of research. It is the micro approach that enables a detailed study of a problem, understanding the historical and cultural aspect. Methodologically, this would mean advocating for the qualitative approach and reliance on the school, class, group or individuals, in order to explore the manifest characteristics of the school community (Spasenović, 2013). However, the question is whether the qualitative approach and the problem with analysis, explanation and prediction provide a "scientific" approach to comparative research. According to everything mentioned above, the answer is yes. The development of the methodological apparatus in data collection and analysis is becoming more and more scientific in nature. In comparative studies, research techniques do not differ much from the techniques used in medicine, psychology and other social sciences. However, comparativists continue to introduce advantages into the research, but also disadvantages that are reflected in personal preference. For instance, a physicist strives for rigorous hypotheses testing and the replication of results, an economist seeks complex connections between education and economic performance and uses statistics, and a historian prefers to use a speculative philosophical approach, relying on invaluable evidence. It is important to emphasize that a comparative study of today's phenomena is not possible without studying the historical aspect (Phillips, 2006).

Research commitment to promote qualitative methodology enables the critical inclusion of the social construction of knowledge, the epistemological relationship of power and the sociocultural development of identity. In this way, academic freedom is preserved due to different epistemology and methodology in comparative research. This also contributes to a richer understanding of reality through original works (Otsuka, 2009; Silova and Brehm, 2010). However, a threat to the qualitative research paradigm is globalization. It contributes to neglecting the culture of mediation of global policies at multiple levels of education and positivist-oriented research (Vulliamy, 2004). On the other hand, this threat reveals the power of the qualitative paradigm in comparative research, as it represents a means of linking theory, policy and practice by establishing local and global connections in policy making. The qualitative approach makes a particularly significant contribution to developing countries, as it provides knowledge about the real experiences of students and teachers (Kazamias, 2001).

The bottom-up approach can help to identify differences between policies and practices for identifying unintended outcomes or processes in their natural environment. It can be concluded that the qualitative approach is an integral part of comparative research or at least should be for a full understanding of the compared phenomena. By using positivist methodology in comparing phenomena, personal or tacit experiential knowledge, historical or social context, political or social values are omitted. Due to the absence of certain elements, the phenomena cannot be systematically re-examined and viewed from 
every aspect (Zha and Tu, 2016).

Noah and Eckstein (1969: 65) single out three methodological phases in comparative research: the first phase characterized as data collection, an encyclopedic and somewhat non-selective approach; the second phase with an emphasis on explanation rather than description that seeks historical and cultural context; the third phase, which is a new mainstream methodology that involves the use of empirical methods of the social sciences and self-awareness of procedures. Kazamias (1961) distinguishes between the new and the old methodology in comparative research. The old is descriptive, prescriptive and indiscriminately mixing "what is" with "what should be". The new methodological approach is philosophical, functional, problematic, more analytical and scientific.

Given the development of the methodological apparatus in stages, the usefulness and value of an appropriate alternative approach becomes confusing. What is quite clear is that with the maturation of comparative research, the tendency of objectivity in the study of education grows. This makes researchers uninterested and ideologically impartial observers of the relationship between school systems (Epstein, 1983).

Based on authors' previous views, it becomes clear that only a combination of qualitative and quantitative methods in comparative research can contribute to a more realistic view of the compared educational phenomena. Zha and Tu (2016) argue that mixed methods fit comparative studies perfectly, as they seek to collect data to make meaningful comparisons about the experience and performance of education systems in different countries. Comparative research by nature attempts to explain why education systems differ and investigates how education relates to broader social factors and forces. Basically, the approach of mixed methods can adequately support the goals of comparative research, provided that the quantitative component serves confirmatory goals, and the qualitative component serves research goals. This view is well-founded because comparative research is interdisciplinary and cross-cultural. Therefore, it is necessary to avoid any possibility of narrowing and suggesting that one program or method is adequate for the complexity of research subjects such as education (Ruscoe and Nelson, 1964; Holmes, 1984).

Theoretical and empirical studies indicate that comparative research can be spoken of as a multimethod form of research. Although importance is given to the quantitative paradigm, the increasing application of the qualitative approach and a combination of different research procedures is seen in comparative research. Regarding the application of comparative research in pedagogy, the micro approach in the perception of education systems is important, as well as the application of the qualitative approach in discovering important pedagogical issues and problems of educational practice.

\section{Function of comparative research in pedagogy}

From the previous sections, it can be concluded that the comparativists of the $19^{\text {th }}$ century put emphasis on national school systems and this approach was maintained until the middle of the $20^{\text {th }}$ century. Research was aimed at collecting data from the national level on the functioning of different segments of the school system, classifications and comparisons. It relied on national characteristics such as: political order, religion, culture and language, in order to interpret the differences (Green, 2003). Comparisons have become a fascination of comparativists, especially today when the international exchange of ideas and practices in the age of globalization is in the spotlight. The value of pedagogy is in providing theoretical and practical knowledge. Its function is not only directed towards the study of teaching and learning. Its role is visible within national systems and the understanding and examination of internal phenomena. The importance of comparative pedagogy is reflected in the increasing application of the potential for the analytical framework (Alexander, 2009). Although the value of comparative pedagogy is highly important, one gets the impression that the areas of comparative interest in education are underrepresented topics, which are closely related to pedagogical issues. Thus, topics that are close to other scientific disciplines such as sociology and economics are more present. The issues and problems that are addressed in comparative research are mostly topics related to social factors that shape education (economic, political, demographic, philosophical, etc.), as well as topics related to various aspects of the education system (Spasenović, 2013). Similarly, Noah (1984) believes that comparative research enables the perception of similarities and differences in pedagogical phenomena in different countries. He points out that it is also necessary to explain the causes or reasons for these similarities or differences. He emphasizes that authoritarian relations in school may indicate authoritarian relations in society (politics) or that an inefficient use of resources intended for education may indicate an inability to use resources effectively in industry or agriculture. Thus, a comparative study of education can be useful for understanding the 
value systems, culture, and progress of the compared societies. Furthermore, the cultural approach essentially encompasses issues related to universal characteristics. Such an approach enables a deeper examination of contemporary phenomena in their historical retrospective and helps the comprehension of the connections between the present and the future in pedagogical processes. In that way, the level of objectivity of the obtained data is raised because real pedagogical phenomena are examined in a sociocultural context (Chigisheva, 2015). The study of other school systems, together with the socio-cultural aspect, enables the verification of the observed regularities in relation to another system which implies different conditions (Spasenović, 2013).

The field of comparative pedagogy is closely related to the processes of globalization, perhaps more than most other areas of academic research. The interest is focused on cross-national analyzes. The field of interest leads researchers to look outside while the influences of that same globalization are happening inside. The cross-national forces of change are reflected in dominant paradigms, methodological approaches and research focuses (Bray, 2002).

Much of contemporary comparative pedagogy has remained narrowly empirical, positivist, or reform-oriented. However, the question arises as to whether comparative research in this regard is needed under the auspices of globalization and the phenomenon of the "global village". Globalization is not far from eliminating diversity in the world, which makes comparison and contrast impossible. If the presence and further contrasts in society are noticed, especially in pedagogical processes, a comparison is possible. Therefore, the focus is no longer on the pure quantification of the characteristics of education systems, but on the nuances that influence the creation of such a system (Green, 2003).

It is evident that there is a general agreement among authors regarding the most general definition of the functions of the comparative study of education. Differences exist in terms of a more specific level. That is why it is important to consider all these levels of functions of the comparative analysis of school systems. It is Noah (1984) who points out the functions of comparative research. As one of the functions, he emphasizes data recording, description and aspects of school systems and their comparison. Comprehending the broader context provides an understanding of the school system and factors (historical, economic, political, etc.) and their interpretation is one of the equally important functions. An important role of comparative research is also evaluation. It provides an opportunity to assess the effectiveness of one's own education system compared to the systems of other countries. The results of international evaluation studies have encouraged many countries to develop new education policy measures and to initiate major reforms. On the other hand, the findings of comparative research are a great help to decision makers in creating education policies and implementing reforms. Comparative research provides new insights into other systems and other environments. This also indicates their function, which includes learning about their problems and the difficulties of the process itself.

Hence, not only is the function of comparative research reflected in determining the similarities and differences of education systems, but there is also a tendency to determine the internal dynamics of educational processes in a particular context. It is precisely these nuances that comprise pedagogical phenomena that cannot be excluded from the study subject. That is why the function of comparative pedagogy is important, because, as Alexander (2009) points out, it reveals the way in which what takes place in the classroom reflects on the whole society.

\section{Place of comparative research in pedagogy}

Based on the considerations in the previous sections, it can be determined that comparative research uses a pluralism of methodological approaches and techniques. Thus, it does not remain on the surface but tends to establish the causes of the differences that exist between the compared objects. In that way, comparative research becomes a significant form of transmission of positive experiences, which enables the correction of educational practice.

The questions that arise from the previous analysis, and which are asked by comparativists, are: why study education systems, especially national ones; what else should comparativists explore and how; what defines the field of comparative pedagogy? Wilson (2003) defines comparative pedagogy as an intersection of the social sciences, education and cross-national study which attempts to use crossnational data to test propositions about the relationship between education and society and between teaching practices and learning outcomes. Its development is influenced by globalization, often mentioned in the previous analysis. Under its influence, the number of student exchanges, online education, crossing state borders, accelerated cultural permeation among nations and educational institutions has increased. On the other hand, international comparison is also facing challenges in these conditions. 
The implications are numerous, among which Marginson and Mollis (2001: 612-613) single out five that reconstruct comparative pedagogy:

1. Analytical framework. Scientists should compare countries with countries in a broader context. At the same time, it is pointed out that global effects are contested and uneven and differ among peoples, regions and institutions.

2. Units of analysis. The traditional comparative map of the world, in which all nations are formally similar and ranked according to the degree of development on a single scale, is more inadequate than ever. It does not explain power relations among nations and hides qualitative national differences. Globalization requires a new geopolitical cartography that follows the flows of global effects and the patterns of imitation, difference, domination and subordination in education policy and practice.

3. Cross-border international education. Cross-border trade in international education has become an important subject of research in itself. Such trade raises questions about the identity of student mobility and the attributes required for teachers, institutions, and systems. Subtopics include tensions between national practices and national cultures, as well as the rapid growth of online education communities.

4. Forms of identity. Globalization opens up a new potential for non-national forms of identity. The traditional focus on the nation-state has diminished supranational cultural and religious identities and obscured intra-national regional diversity in educational participation, resourcing, and outcomes.

5. The impact of globalization at the national level. Modern education systems are still organized at the local and national level and are still subject to national regulation. The trends of increased mobility and cosmopolitanism have major implications for the policy of preparing citizens in education. Therefore, the need for further research into the measures of international agencies and other forms of national education policy is pointed out.

Thus, the importance of the starting point that comparative education has a very important, but also a different role in the era of globalization is recognized. This is why it is seen as a means and aid to empower the academic community and practitioners in understanding the changes that have taken place. This does not mean, however, that the nation-state should be rejected as a unit of analysis, but only focus on the key issues affecting education within individual countries. Based on these conclusions, it follows that the implementation of comparative research in education can be useful for both pedagogical theory and practice. Phillips (1999: 16) recognizes the importance of comparative research in the following:

1. it offers criteria (standards) in relation to which the success of the functioning of education systems is assessed;

2. it provides information of a descriptive and explanatory nature that enables the consideration of various solutions in different contexts;

3. it helps in considering alternative solutions in relation to those that exist in their own system;

4. it indicates the possible consequences of certain actions by considering the experiences of other countries;

5. it plays a very important instructive and supportive role in the process of planning education reforms in cases where it is useful to look at the experiences of others;

6. it contributes to the development of theoretical knowledge within which educational phenomena are described and analyzed;

7. it contributes to the strengthening of cooperation and mutual understanding between nations by perceiving cultural similarities and differences, as well as their interpretation;

8. it is of great intellectual importance, in the same sense as comparative studies in the field of religion, literature, law and the like.

The need for comparative research is reflected in the study of precedents in other countries for the purpose of planning and reforming education (Zha and Tu, 2016). However, the role and place of pedagogy in comparative research is in examining and understanding educational phenomena, processes and conditions. Without pedagogical knowledge, comparative research loses the possibility of the pedagogical projection of school systems development as well as of social development.

\section{Conclusion}

The aim of this study includes the analysis of the theoretical understandings of the role of comparative research in the cognition of pedagogical phenomena as well as the transformation of the comparative methodological apparatus in the contemporary context. Given this intention, it can be concluded that the analyzes conducted in this study indicate the importance of using the quantitative and the qualitative paradigm, as well as their combination in the examination of different phenomena and processes. The 
pluralism of the methodological apparatus, approaches and techniques makes comparative research unique in its contribution to pedagogical science, because it considers pedagogical processes in all their complexity. Precisely because of their multidimensionality and complexity, comparative research has an academic and practical contribution to the study of pedagogical phenomena and changing education policies. Their application encourages the exchange of intellectual goods and partnerships in the exchange of successful practices. On the other hand, pedagogical phenomena are an inexhaustible source of cognition, because they contain a humanistic orientation which is always the subject of interest of comparativists. That is why pedagogical science offers a new civilizational approach, with different views on the development of education systems.

The significance of this study is recognized first in the analysis of the roles and functions of the methodology of comparative research in pedagogy. The insight gained when it comes to the methodological apparatus is that all methods and techniques that can be found in pedagogical research are present in comparative research. The methodology of comparative research enables the discovery of important pedagogical issues and problems concerning the contribution to the development of education systems. It provides an opportunity for a deeper understanding of the value systems, culture and progress of the compared societies (Stanković, Maksimović and Osmanović, 2018). Comparative research in pedagogy is important in terms of offering the standards of success, interpreting phenomena, giving solutions, pointing out consequences and interpreting cultural similarities and differences. On the other hand, their focus on comparing external rather than internal processes and phenomena is noticeable. In this regard, the importance of the methodological openness of comparative research, i.e. the connection between the quantitative and the qualitative paradigm, is pointed out, in order to strengthen research capacities for its future development in pedagogical science.

\section{Conflict of interests}

The authors declare no conflict of interest.

\section{References}

Alexander, R. (2009). Towards a comparative pedagogy. In R. Cowen, \& A.M. Kazamias (Eds.), International handbook of comparative education (pp. 923-939). Dordrecht: Springer. http://dx.doi.org/10.1007\%2F978-1-4020-6403-6_59

Bray, M. (2002). Comparative education in the era of globalisation: Evolution, missions and roles. Revista Española de Educación Comparada, 8, 115-135. Retrieved from https://bit.ly/2JwbQT7

Bray, M., Adamson, B., \& Mason, M. (2007). Comparative education research: Approaches and methods. Comparative Education Research Centre. The University of Hong Kong. https://psycnet.apa.org/doi/10.1007/978-1-4020-6189-9

Chigisheva, O. (2015). Globalization and its influence on comparative education methodology. Bulgarian Comparative Education Society, 13(2), 131-137. Retrieved from https://files.eric.ed.gov/fulltext/ED568931.pdf

Crossley, M. (2000). Bridging Cultures and Traditions in the Reconceptualisation of Comparative and International Education. Comparative Education, 36(3), 319-332. https://doi.org/10.1080/713656615

Dyankova, G. (2018). Research of cognitive exchange specifics in teachers academic training. International Journal of Cognitive Research in Science, Engineering and Education (IJCRSEE), 6(3), 1-14. https://doi.org/10.5937/ijcrsee1803001D

Epstein, E.H. (1983). Currents left and right: ideology in comparative education. Comparative Education Review, 27(1), 3-29. Retrieved from https://bit.ly/3mkDDUZ

Epstein, E.H. (2008). Setting the normative boundaries: Crucial epistemological benchmarks in comparative education. Comparative Education 44(4), 373-386. https://doi.org/10.1080/03050060802481405

Epstein, E.H. (2017). Is Marc-Antoine Jullien de Paris the "father" of comparative education? Compare, 47(3), 317-331. https:// doi.org/10.1080/03057925.2016.1254542

Green, A. (2003). Education, globalisation and the role of comparative research. London Review of Education, 1(2), 83-97. https://doi.org/10.1080/1474846032000098464

Halls, W.D. (1990). Comparative education: contemporary issues and trends. London: J. Kingsley Publishers.

Holmes, B. (1984). Paradigm shifts in comparative education. Comparative Education Review, 28(4), 584-604. https://doi. org/10.1086/446469

Kaloyannaki, P., \& Kazamias, A. M. (2009). The modernist beginnings of comparative education. The proto-scientific and the reformist-meliorist administrative motif. In R. Cowen, \& A.M. Kazamias (Eds.), International Handbook of Comparative Education (pp. 11-30). Dordrecht: Springer.

Kazamias, A.M. (1961). Some old and new approaches to methodology in education. Comparative Education Review, 5, 9096. https://doi.org/10.1086/444876

Kazamias, A.M. (2001). Re-Inventing the historical in comparative education: Reflections on a protean episteme by a contemporary player. Comparative Education, 37(4), 439-449. https://doi.org/10.1080/03050060120091247

Manzon, M. (2018). Origins and traditions in comparative education: Challenging some assumptions. Comparative education, 54(1), 1-9. https://doi.org/10.1080/03050068.2017.1416820

Marginson, S., \& Mollis, M. (2001). The door opens and the tiger leaps: Theories and reflexivities of comparative education for a global millennium. Comparative Education Review, 45(4), 581-615. https://doi.org/10.1086/447693

Mattheou, D. (2009). The scientific paradigm in comparative education. In R. Cowen, \& A.M. Kazamias (Eds.), International 
Handbook of Comparative Education (pp. 11-30). Dordrecht: Springer.

Noah, H. J., \& Eckstein, M. A. (1969). Toward a Science of Comparative Education. London: Macmillan. https://doi. org/10.1080/00131727009340421

Noah, H.J (1984). The use and abuse of comparative education. Comparative Education Review, 28(4), 550-562. https://doi. org/10.1086/446467

Otsuka, Y. (2009). The challenges of fieldwork in comparative education studies in Japan: A methodological consideration. Educational Studies in Japan: International Yearbook, 4, 37-51. Retrieved from https://files.eric.ed.gov/fulltext/ EJ912718.pdf

Phillips, D. (1999). On comparing. In R. Alexander, P. Broadfoot \& D. Phillips (Eds.), Learning from comparing: New directions in comparative educational research, context, classrooms and outcomes (pp. 15-20). Oxford: Symposium books.

Phillips, D. (2006). Comparative education: Method. Research in Comparative and International Education, 1(4), 304-319. https://doi.org/10.2304\%2Frcie.2006.1.4.304

Ruscoe, G. C., \& Nelson, T.W. (1964). Prolegomena to a definition of comparative education. International Review of Education, 10(4), 385-392. https://doi.org/10.1007/BF01416166

Rust, V.D., Soumaré, A., Pescador, O., \& Shibuya, M. (1999). Research strategies in comparative education. Comparative Education Review, 43(1), 86-109. Retrieved from https://bit.ly/2KUMTBr

Schneider, F., Kirkpatrick, U., Fellner, L., \& Bereday, G. (1961). The immanent evolution of education: a neglected aspect of comparative education. Comparative Education Review, 4(3), 136-139. https://doi.org/10.1086/444845

Silova, I., \& Brehm, W.C. (2010). For the love of knowledge: William W. Brickman and his comparative education. European Education, 42(2), 17-36. https://doi.org/10.2753/EUE1056-4934420202

Spasenović, V. (2013). Skolski sistemi iz komparativne perspektive [School systems from a comparative perspective]. Belgrade: Institute of Pedagogy and Andragogy, Faculty of Philosophy.

Stanković, Z., Maksimović, J., \& Osmanović, J. (2018). Cognitive theories and paradigmatic research posts in the function of multimedia teaching and learning. International Journal of Cognitive Research in Science, Engineering and Education (IJCRSEE), 6(2), 107-114. https://doi.org/10.5937/ijcrsee1802107S

Tamtik, M. (2014). Book review. Canadian and International Education, 43(2), 1-6. Retrieved from https://bit.ly/3muEna8

Vulliamy, G. (2004). The impact of globalization on qualitative research in comparative and international education. Compare, 34(3), 261-283. https://doi.org/10.1080/0305792042000257112

Wilson, D. (2003). The future of comparative and international education in a globalised world. International Review of Education, 49(1-2), 15-33. Retrieved from https://bit.ly/2JdlwRB

Zha, Q., \& Tu, D. (2016). Doing mixed methods research in comparative education: Some reflections on the fit and a survey of the literature. In A. W. Wiseman \& E. Anderson (Eds.), Annual Review of Comparative and International Education 2015 (pp. 165-191). Emerald Group Publishing Limited. https://doi.org/10.1108/S1479-367920150000028014 